\title{
JRC2011-56103
}

\section{PRELIMINARY RECONSTRUCTION OF THE NOVEMBER 30, 2007 CHICAGO, IL RAIL COLLISION}

\author{
Patricia Llana \\ David Tyrell \\ Volpe National Transportation Systems Center \\ US Department of Transportation \\ Cambridge, MA 02142
}

\begin{abstract}
The Volpe Center is supporting the Federal Railroad Administration in performing rail passenger equipment crashworthiness research. The overall objective of this research is to develop strategies for improving structural crashworthiness and occupant protection. A field study of passenger train accidents is being conducted to investigate the causal mechanisms of the injuries incurred by train occupants. The investigation of the November 30, 2007 collision in Chicago, IL has provided preliminary data on the structural damage as well as occupant injuries resulting from the impact. This data will be used in simulations to guide the development of crashworthiness strategies.
\end{abstract}

\section{INTRODUCTION}

The Volpe Center has been supporting the Federal Railroad Administration (FRA) in performing rail passenger equipment crashworthiness research. The overall objective of this research has been to develop strategies for incrementally improving structural crashworthiness and occupant protection in passenger trains. This is achieved by preserving the occupant volume and limiting the forces and accelerations imparted to the occupants in passenger train collisions, thereby preventing life-threatening injuries.

The objective of the equipment crashworthiness research is to evaluate both the equipment structural behavior and the occupant response in passenger train collisions. Exterior and interior configurations that warrant improvement are identified, and then improved crashworthiness strategies for those configurations are developed [1]. The first step in the research process is to conduct accident investigations to identify the most common collision scenarios, determine the related modes of deformation of the exterior and interior equipment, and ascertain the resulting occupant injuries and their severity. In subsequent steps, dynamic and quasi-static full-scale testing and computer modeling are conducted to measure the equipment behavior and occupant response and evaluate candidate crashworthiness strategies [2]. This approach utilizes the data obtained from accident investigations efficiently in order to prevent similar injuries in the future. The general approach to developing crashworthiness strategies is summarized in Figure 1.

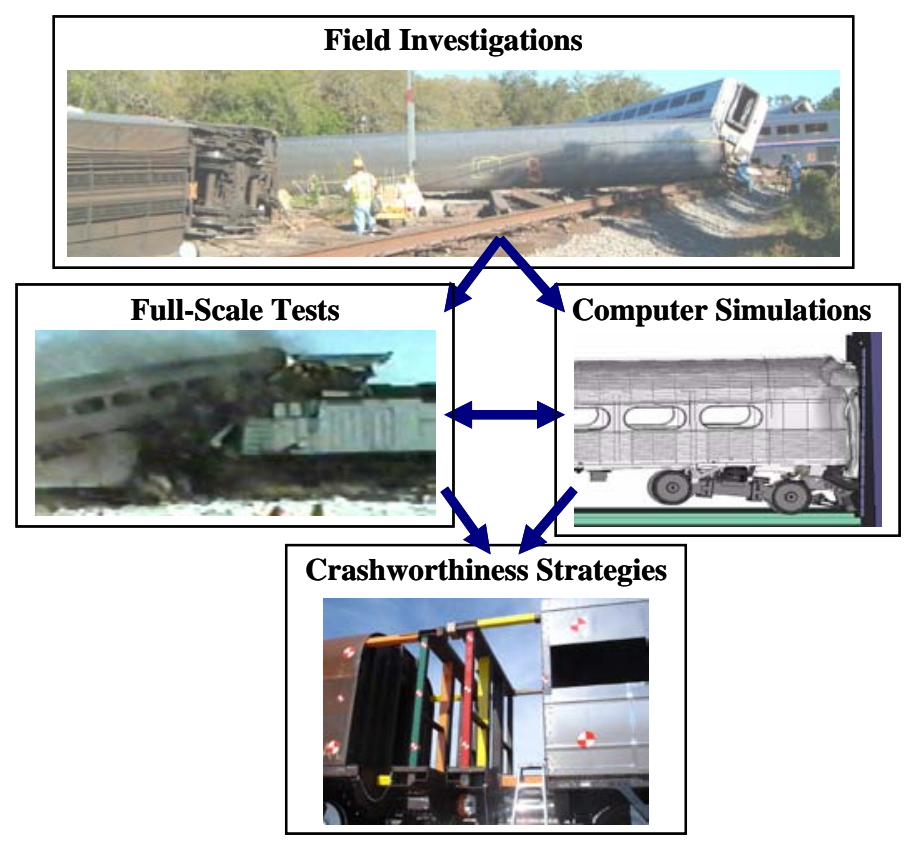

Figure 1. Approach to crashworthiness studies.

This paper describes the preliminary reconstruction of the Chicago, Illinois collision between a passenger train and a freight train from data gathered in the field investigation [3]. The primary objective of a field investigation is to determine how the occupants were injured and to ascertain the causal mechanisms for their injuries. The data gathered includes the 
final position of the equipment, the structural damage of the equipment, the wayside evidence, the event recorder data, the interior fixture damage, passenger injury evidence, occupant interviews, and medical records. The data is then interpreted in order to synthesize the impact sequence of events, the train dynamics, the colliding car interaction, the amount of car crush, the loss of interior volume, and the occupant dynamics.

This paper will detail the structural damage and passenger injuries incurred during this collision. Additionally, information from interviews of both the operating engineer and the relief engineer will be provided. A discussion of what has been learned from the accident investigation will be presented and the next steps in the process will be outlined.

\section{PRELIMINARY RECONSTRUCTION}

On November 30, 2007, Norfolk Southern (NS) freight train $23 \mathrm{M}$ was stopped on a main track of NS's Dearborn Division in Chicago, Illinois. A westbound Amtrak passenger train was routed to the same track and given a restricted signal. At approximately 11:30 am C.S.T., the passenger train struck the rear end of the freight train at a speed of approximately $33 \mathrm{mph}$. The passenger train consisted of a P42 General Electric (GE) leading locomotive and three coach cars. The freight train was led by two locomotives followed by 20 multi-platform intermodal cars. Thus, the locomotive in the passenger train collided with the rear of the last freight car in the freight train. Figure 2 and Figure 3 show photographs of a freight car and a locomotive, respectively, which are very similar to the equipment involved in the accident. These photographs indicate what the interacting equipment looked like prior to impact.

There were no fatalities caused by the accident and only minor injuries were incurred by the passengers and crew. However, the engineers located within the operator's cab at the time of impact sustained more severe injuries than the passengers and crew located within the coach cars. This was due to the fact that the locomotive sustained most of the exterior and interior structural damage and bore the brunt of the impact, creating a situation close to life threatening within the cab.

What helped prevent the occurrence of fatalities was that the passenger train remained in line and the locomotive crushed and overrode the freight car rather than being deflected laterally. In a train-to-train collision, passenger trains will typically buckle out laterally either in a relatively small amplitude sawtooth pattern or in a relatively large amplitude zigzag pattern due to the linkage behavior of the couplers. In this accident, there was no lateral buckling because the locomotive overrode the freight car. If the passenger cars had sawtoothed or zigzagged with respect to each other and derailed, there is a very high likelihood that the train would have collided with the trains running on both adjacent tracks, resulting in more severe injuries and possibly fatalities in all of the trains involved.

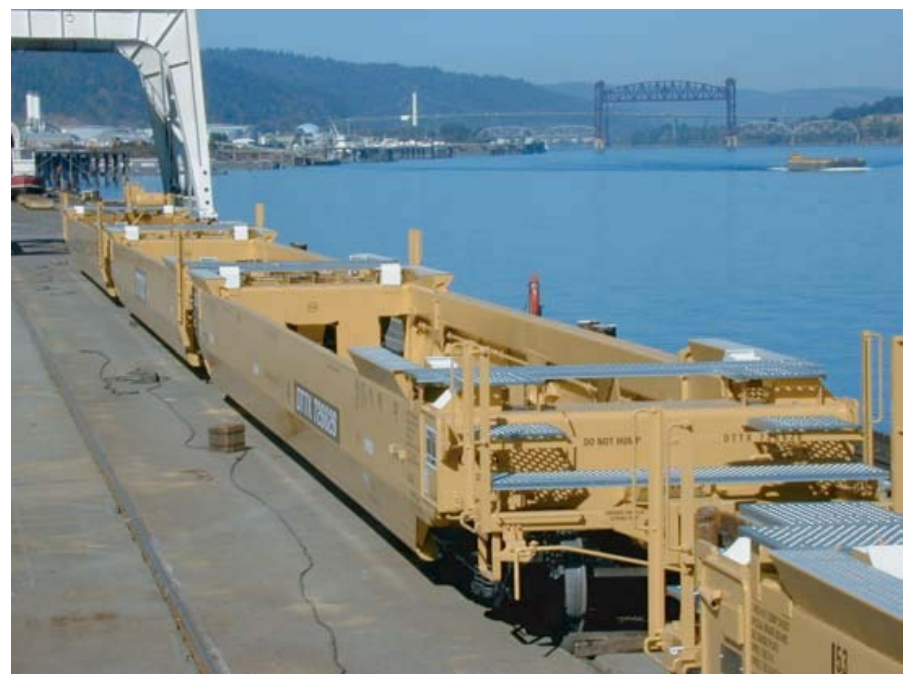

Figure 2. Example of the freight car involved in the accident [4].

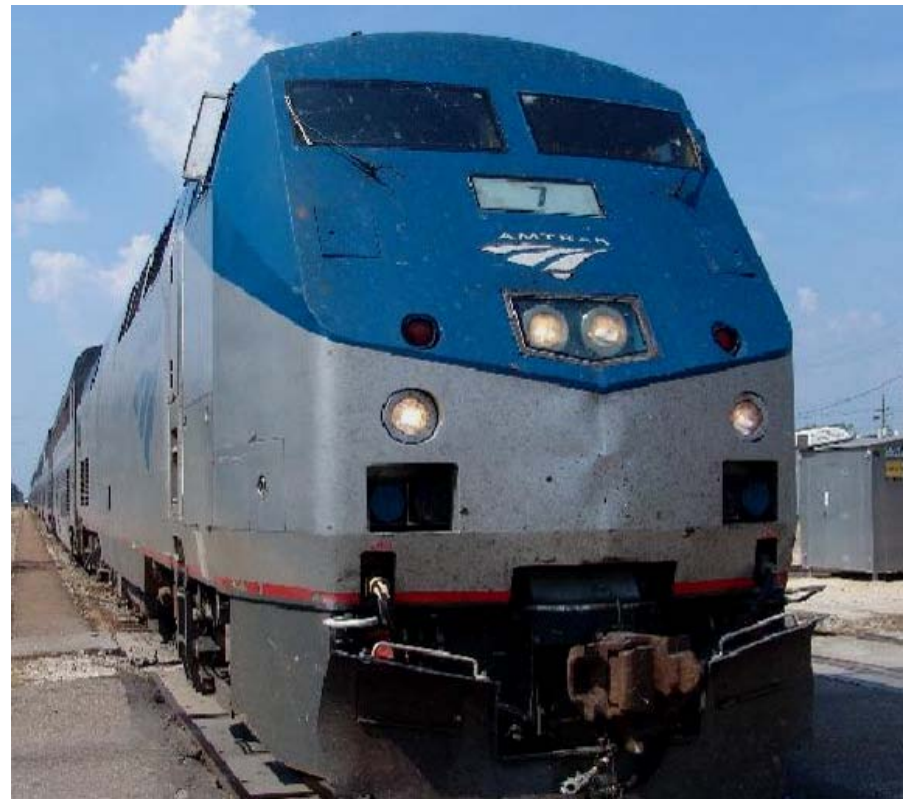

Figure 3. Example of the locomotive involved in the collision [5].

The final position of the equipment (shown in Figure 4), the structural damage of the equipment, the wayside evidence, and the event recorder were interpreted in order to synthesize the impact sequence of events, broken down into a series of phases shown in Figure 5. 


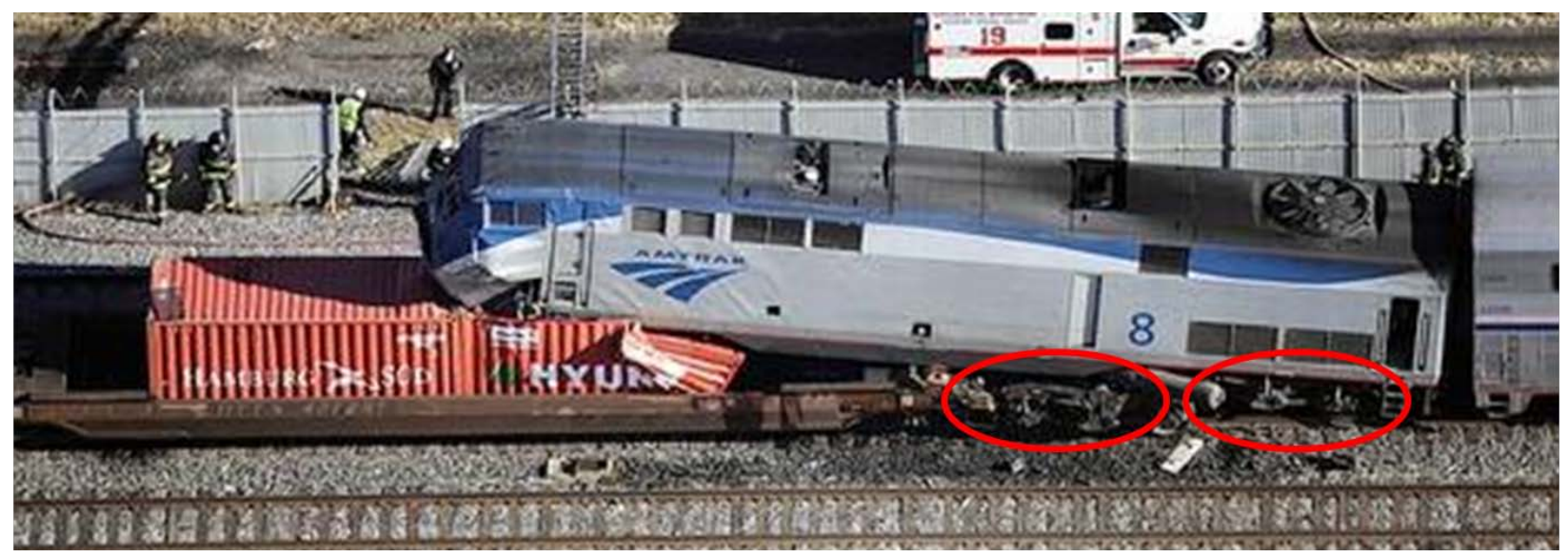

Figure 4. Final position of the locomotive and freight car. The locomotive came to a stop on top of the freight car [6].

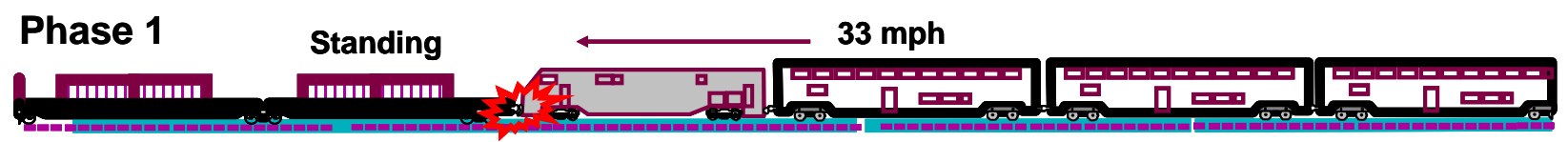

Phase 2

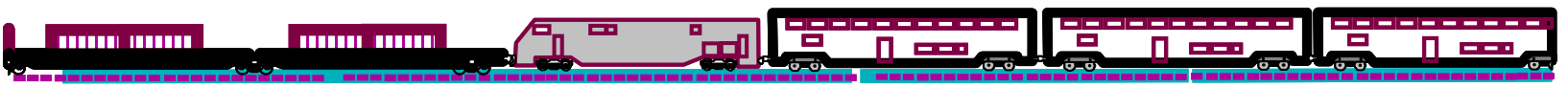

Phase 3

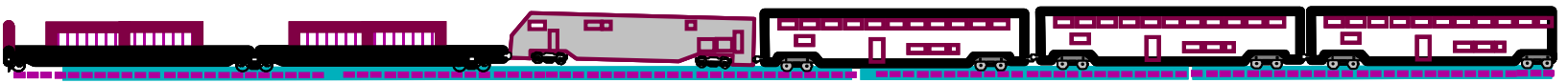

Phase 4

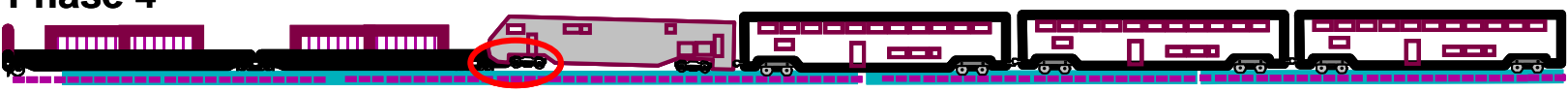

Phase 5

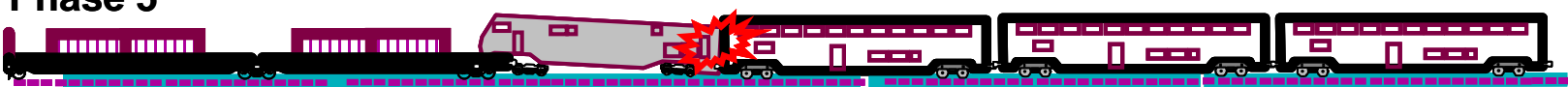

Phase 6
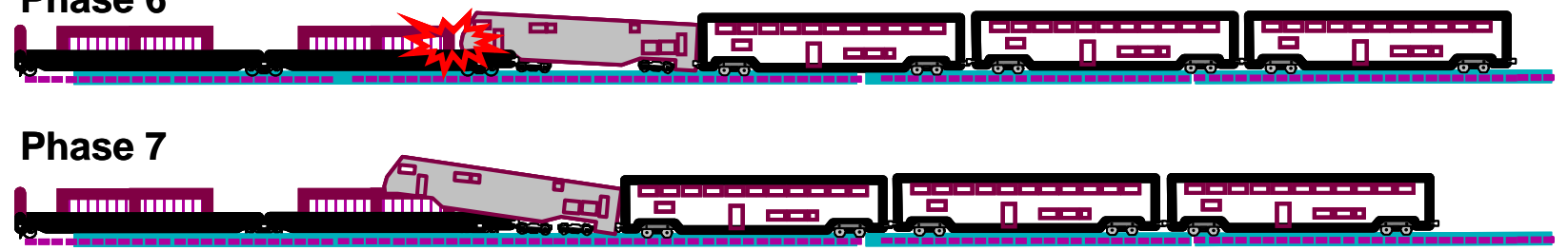

Figure 5. The impact sequence was broken down into phases.

The phases of the impact sequence are:

Phase 1: Contact of the couplers;

Phase 2: Both draft gears bottomed out;

Phase 3: Locomotive began to climb rear of freight car;

Phase 4: Locomotive lead truck engaged freight car;

Phase 5: Locomotive roof engaged lead passenger car;

Phase 6: Locomotive striker engaged freight container;

Phase 7: Locomotive crushed two containers and passenger train came to a stop.
Detailed descriptions and photographs of each phase are provided below. In the last phase of the impact, the passenger train came to a stop with the locomotive resting on top of the last freight car, as shown in Figure 4. A photograph of the impacted end of the locomotive is shown in Figure 6.

Phase 1: Contact of the couplers

In Phase 1, there was knuckle-to-knuckle contact of both couplers, as shown in Figure 5. The knuckle of the locomotive coupler broke off and a piece of the knuckle of the freight car 
also broke off. Figure 7 shows what remained of both couplers after the accident.

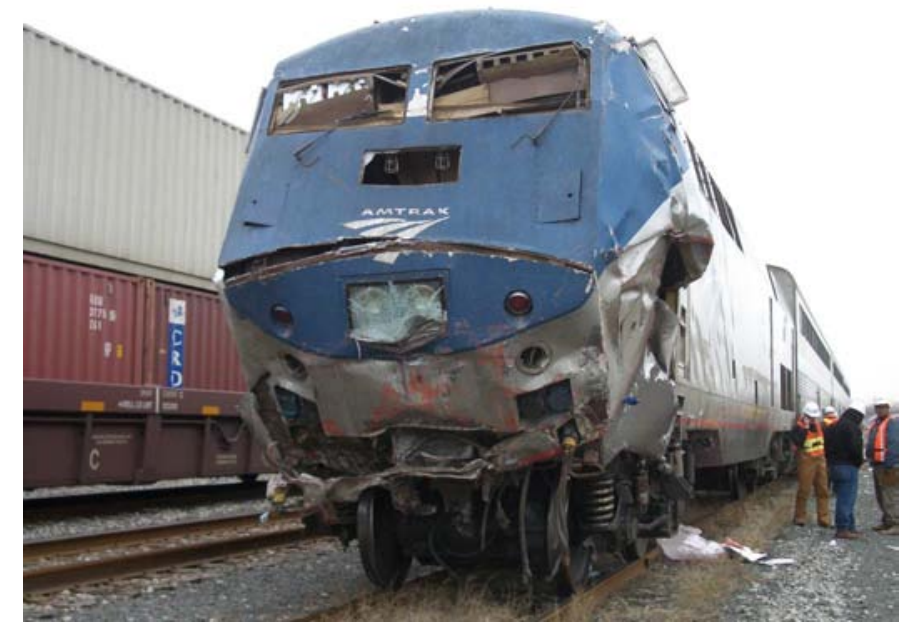

Figure 6. Impacted end of locomotive.

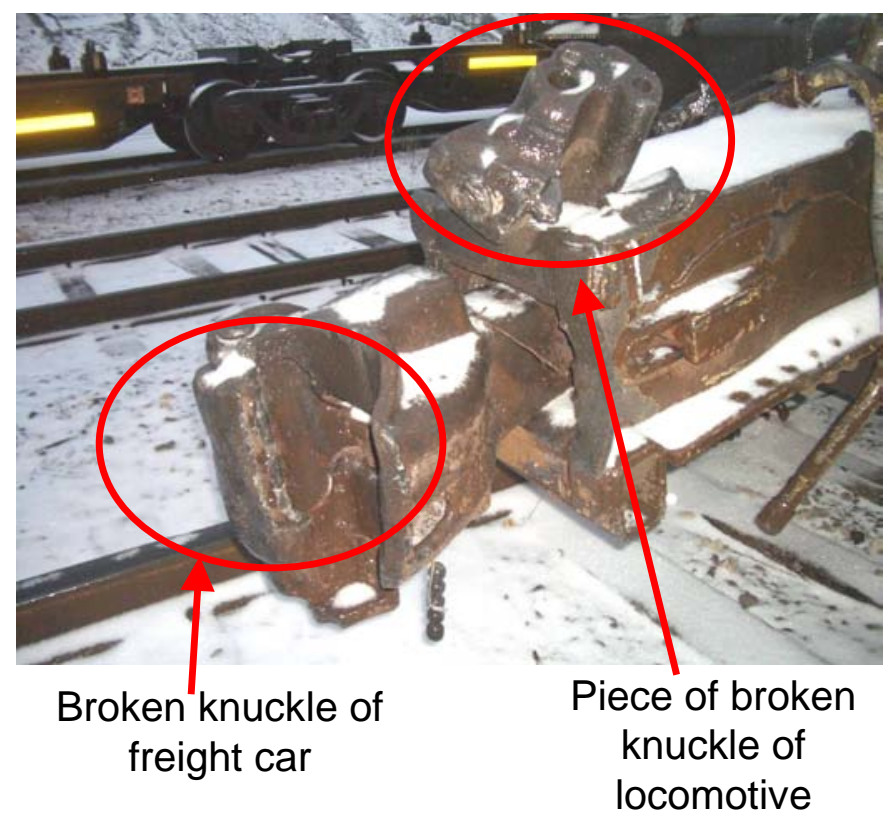

Figure 7. Locomotive and freight car couplers.

\section{Phase 2: Both draft gears bottomed out}

In Phase 2, the locomotive and the freight car couplers moved straight back and both draft gears bottomed out, as shown in Figure 5. Both couplers remained in line and did not swing out laterally. There was little damage to either bellmouth. This was instrumental in keeping both trains mostly in line during the collision sequence. Had either of the couplers swung out, it is very likely that the passenger train would have derailed laterally. This lateral motion would have caused the passenger train to collide with the trains passing by on the adjacent tracks, resulting in a much more severe accident. Figure 8 shows the broken coupler shank of the locomotive.

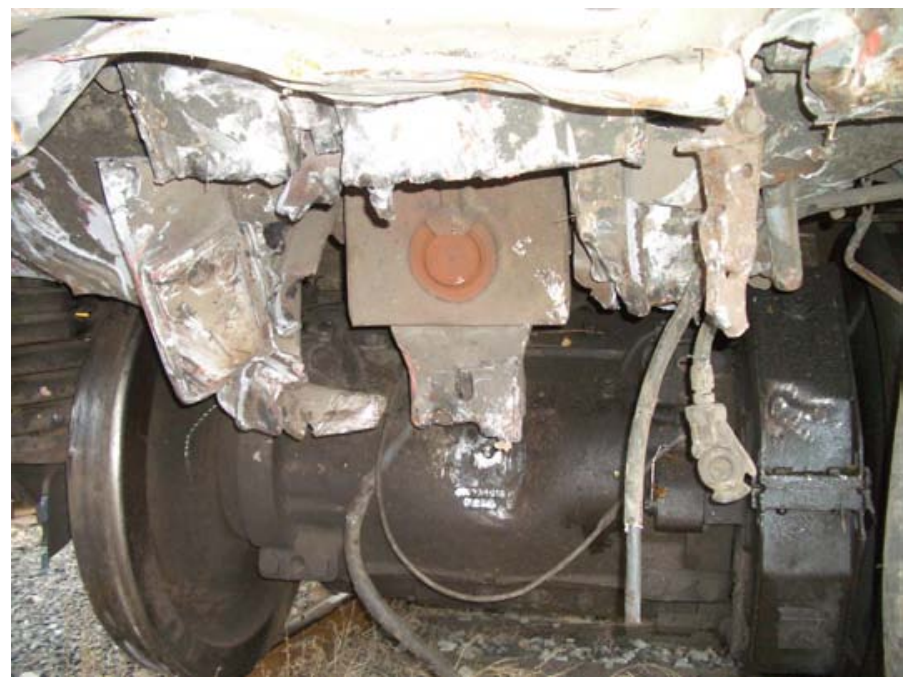

Figure 8. Deformed locomotive draft gear housing and coupler.

Phase 3: Locomotive began to climb rear of freight car

In Phase 3, the locomotive coupler carrier failed and the draft sill of the freight car deformed downward. The deformed draft sill effectively acted as a ramp to enable the locomotive to begin to climb the freight car, as shown in Figure 5. Figure 9 shows the freight car draft sill deformed downward at an angle. The locomotive climbed the freight car, which allowed the trains to remain in line. Again, had the cars sawtoothed or zigzagged with respect to each other and derailed, there is a very high likelihood that the train would have collided with the trains running on both adjacent tracks, resulting in more severe injuries and possibly fatalities in all of the trains involved.

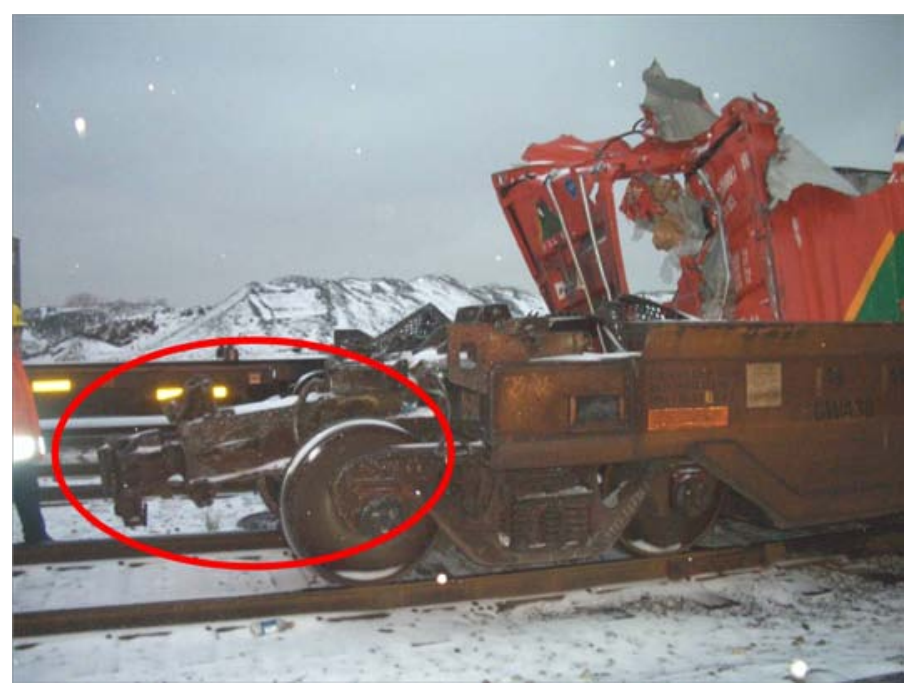

Figure 9. Deformed draft sill of freight car.

Phase 4: Locomotive lead truck engaged freight car

In Phase 4, the locomotive draft gear housing crushed back and up and the locomotive lead truck engaged the freight car. Figure 
8 shows the broken coupler shank of the locomotive and the fractured sides of the draft gear pocket. Figure 8 also shows the indentation that the coupler shank left on the front truck of the locomotive. The coupler shank was most likely pinned between the lead truck of the locomotive and the rear of the freight car. The deformation of the locomotive draft gear housing caused the nose of the locomotive to roll under and push up towards the operator's cab compartment, as shown in Figure 10. Figure 10 also illustrates the resulting deformation of the underframe, which caused a loss of occupant volume in the cab compartment. The nose rolling under also caused the desktop components of the cab to roll forward and push through the front windows of the cab compartment, as shown in Figure 11. Again, the majority of the motion and deformation was in the longitudinal direction, with very little motion or deformation laterally. Had there been more of a lateral component, a much more severe accident would have resulted.

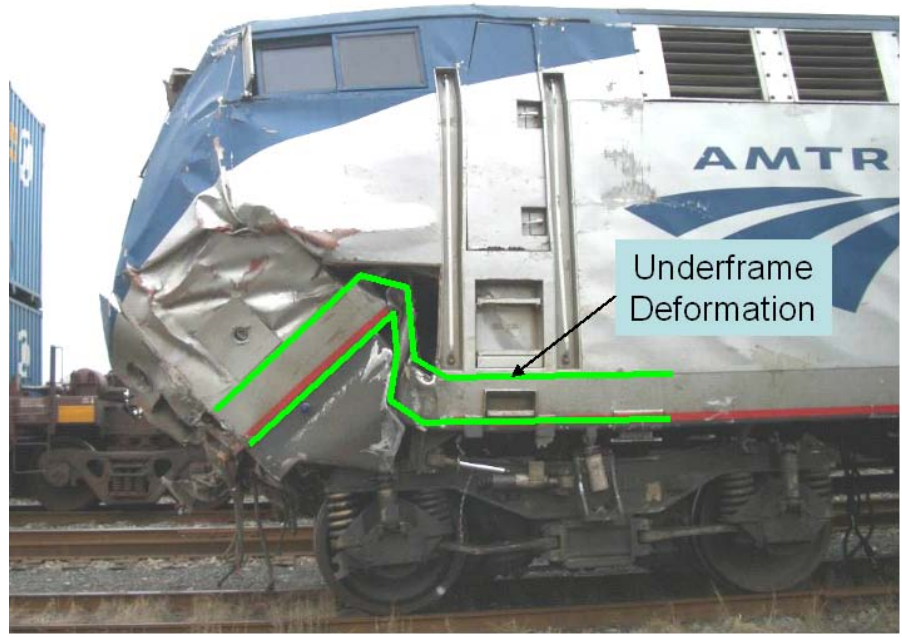

Figure 10. Locomotive nose damage.

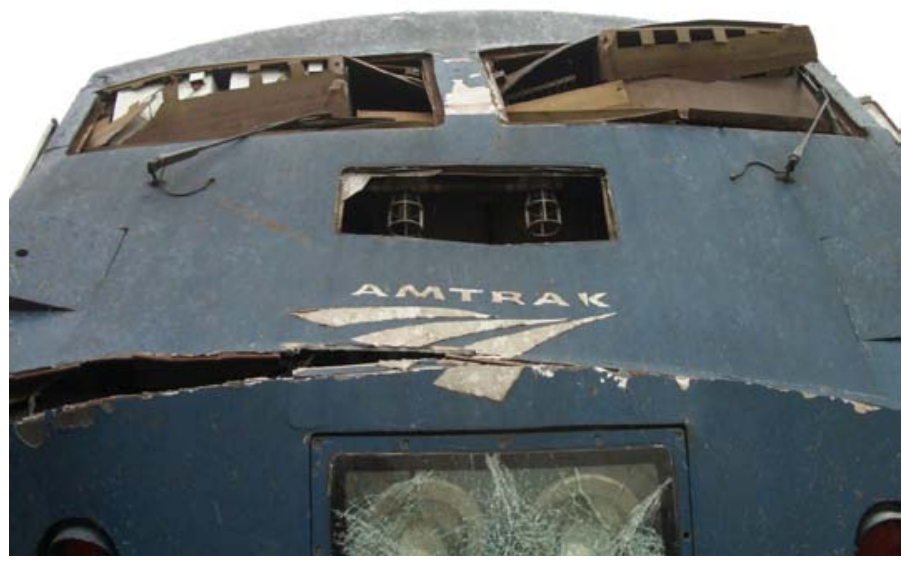

Figure 11. Locomotive desktop components in windows.

Phase 5: Locomotive roof engaged lead passenger car

In Phase 5, the locomotive striker engaged the freight car bolster, the lead truck of the locomotive was sheared off, and the rear of the roof of the locomotive engaged the lead passenger car collision posts as the locomotive tilted in its climb. The damage to the diaphragm of the first passenger car is shown in Figure 12. This was the extent of the exterior damage incurred by the coach cars; there was no other exterior damage. The coach cars and their couplers stayed in line for the duration of the accident with no damage occurring at the coach car interfaces.

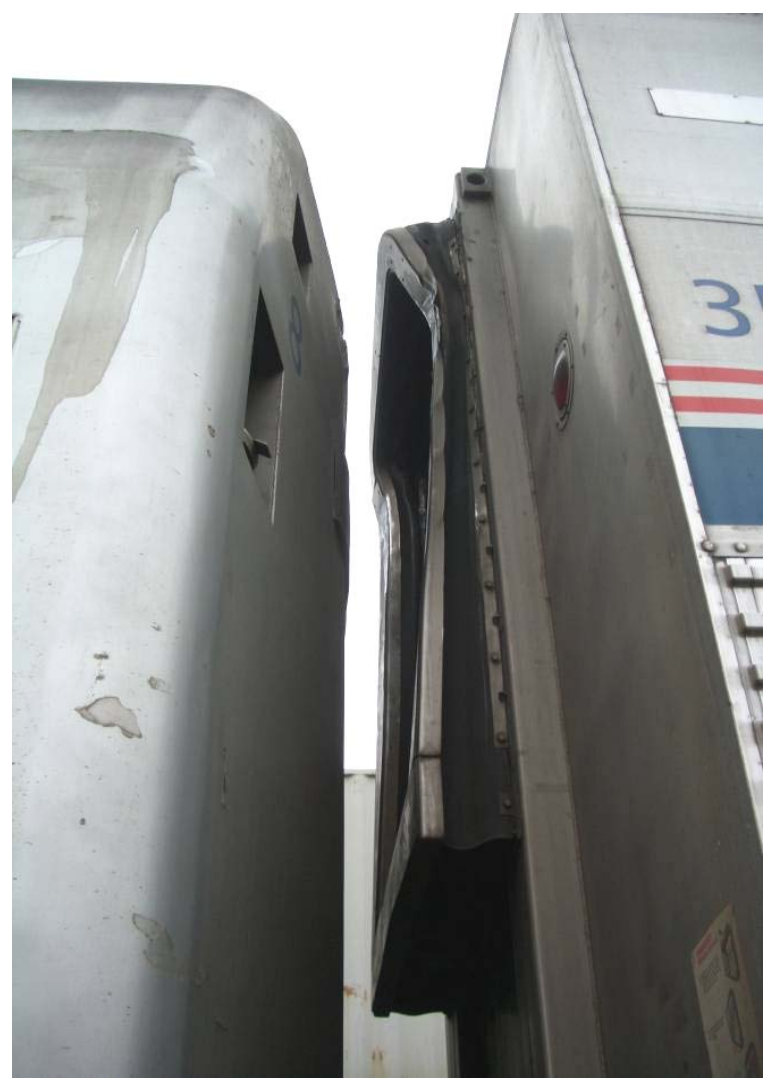

Figure 12. Damage to diaphragm of first passenger car.

\section{Phase 6: Locomotive striker engaged freight container}

In Phase 6, the locomotive striker engaged the rear container of the freight car and the locomotive wheel cut into the fuel tank. The angled freight car draft sill and tucked-in locomotive nose acted together to allow the locomotive to continue to climb the freight car. All of the locomotive motion was moving forward rather than laterally. The post-impact locations of the lead and rear trucks of the locomotive are indicated by the two small red circles in Figure 4. The lead truck was left behind as the locomotive climbed over the rear of the freight car. The photograph shows the lead truck of the locomotive located underneath the locomotive, just in front of the rear truck.

In this phase, the locomotive fuel tank was damaged by the rear wheel of the front truck as the locomotive climbed the freight car. The damage to the fuel tank, as well as a diagram depicting how the damage occurred, is shown in Figure 13. The rear wheel of the locomotive front truck was still spinning when it contacted the slope sheet of the fuel tank. As the 
locomotive climbed the freight car, the spinning wheel fractured the slope sheet then penetrated the corner of the fuel tank baffle. Approximately 300 gallons of diesel fuel spilled from the tank.

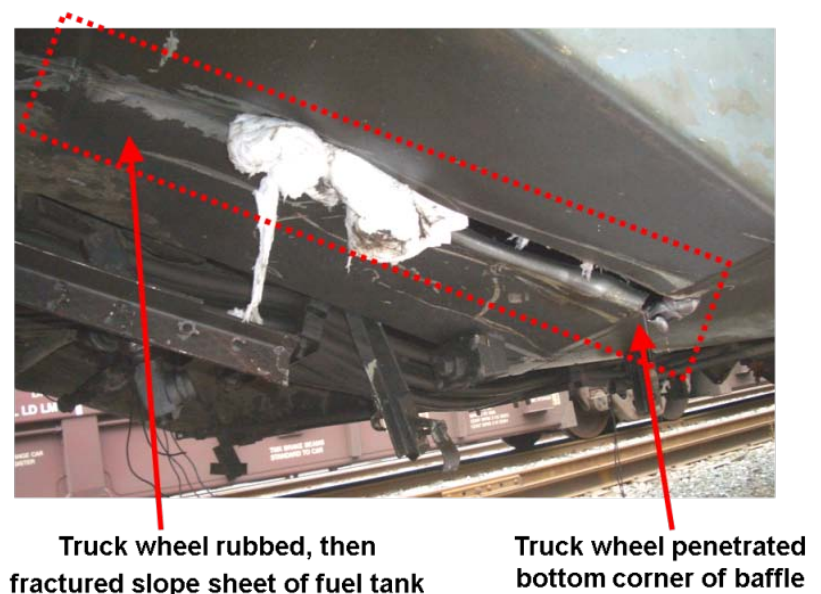

\section{Side view of locomotive fuel tank}

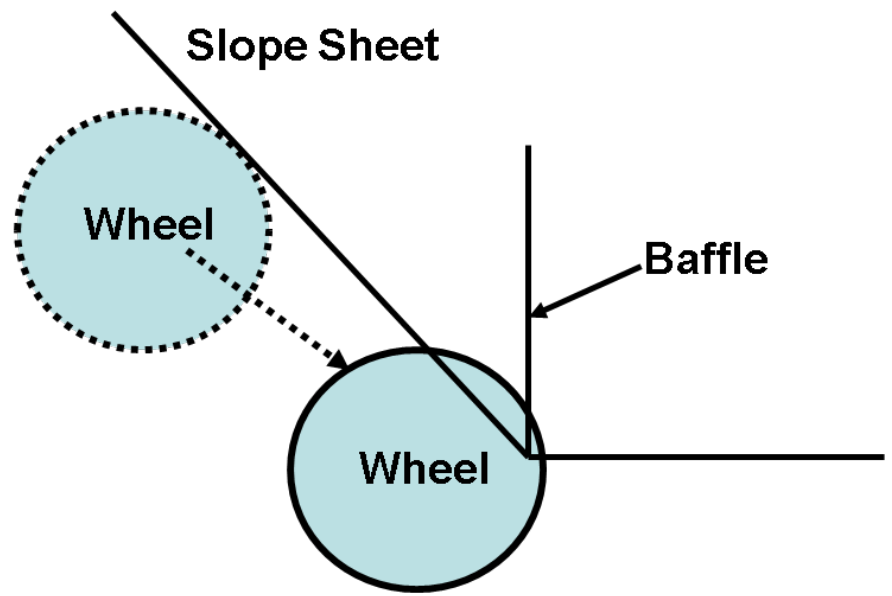

Figure 13. Fuel tank damage.

Phase 7: Locomotive crushed two containers and passenger train came to a stop

In Phase 7, the locomotive crushed the rear container and part of the front container of the freight car. A photograph of the locomotive at rest on top of the freight car is shown in Figure 14. The crushing of both containers absorbed the last of the locomotive kinetic energy and the passenger train finally came to a stop with the locomotive resting on top of the freight containers at an angle. The three trailing coach cars remained upright and the couplers remained coupled. Only the locomotive derailed; the three coach cars remained on the track. Almost all of the exterior damage to the passenger train was sustained by the locomotive. The locomotive experienced severe damage to its nose and underframe, with approximately $5 \mathrm{ft}$. $(1.5 \mathrm{~m}$.) of total crush, as well as wrinkling of both side walls, damage to the rear roof due to contact with the first coach car, and the shearing off of its lead truck. The wrinkles on the side of the locomotive body can be seen near the Amtrak symbol in Figure 14. The exterior damage to the coach cars was limited to the diaphragm of the first coach car, as shown in Figure 12.

Figure 14 shows the adjacent tracks on both sides of the trains involved in the collision. At the time of the collision, there were trains running on both adjacent tracks. Again, had the passenger train not climbed the freight car, the couplers would have caused the cars to sawtooth laterally. This lateral buckling is typical and if it had occurred in this accident, the passenger train could have impacted the trains running on both adjacent tracks, resulting in a more severe accident.

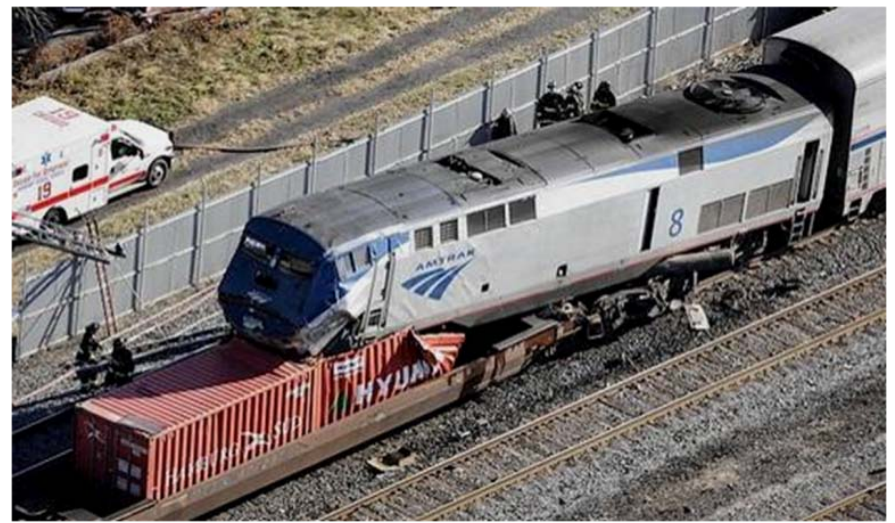

Figure 14. The locomotive came to a stop on top of the rear freight car [6].

\section{INTERIOR DAMAGE}

The impact between the locomotive and the freight car caused the nose of the locomotive to roll under and push upward, resulting in the underframe deforming upward towards the operator's cab. This deformation caused the desktop components of the cab to roll forward and push through the front windows of the cab compartment, as shown in Figure 11. The deformation of the underframe also caused catastrophic failure of the floor of the cab, resulting in the floor and the seats in the cab to be pushed upward. Figure 15 is a photo of the cab interior that shows the window components pushed through the windows, the raised floor, and the relief engineer's seat displaced upward and pushed into the ceiling of the cab. Figure 16 shows the distance the floor of the cab was raised, approximately $1.5 \mathrm{ft}$. (0.45 m.).

The structural damage to the interiors of the coach cars was minor in comparison to the locomotive interior. All of the coaches were equipped with seat pairs that can be rotated $180^{\circ}$ to face either forward or backward. After the accident, two seat pairs in the first coach car, four seat pairs in the middle coach car, and three seat pairs in the last coach car were all rotated with respect to their original positions. Their seat latches had failed to secure the seat pairs in the locked position. Figure 17 shows one of the rotated seat pairs in the third coach car. 


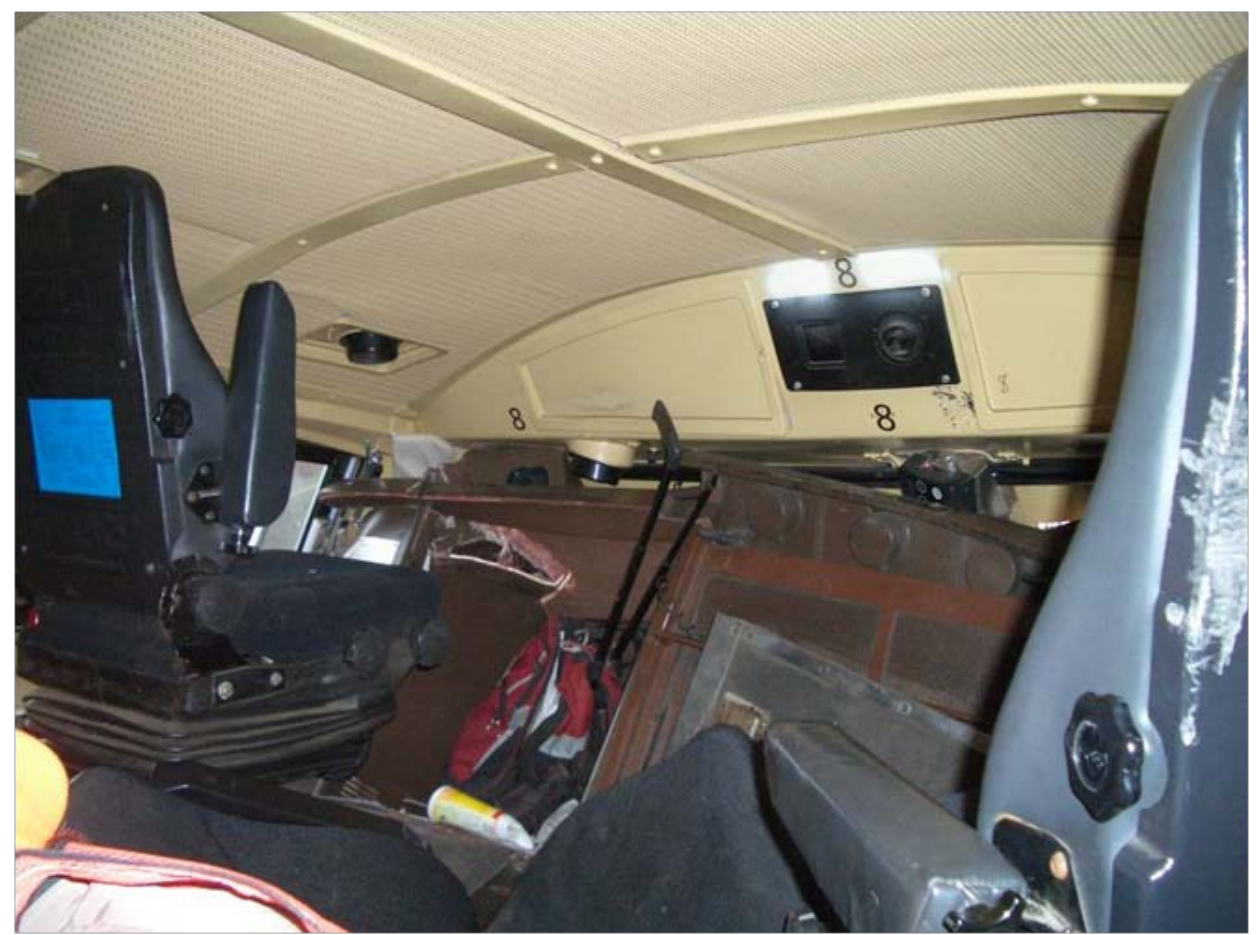

Figure 15. Locomotive interior cab damage.

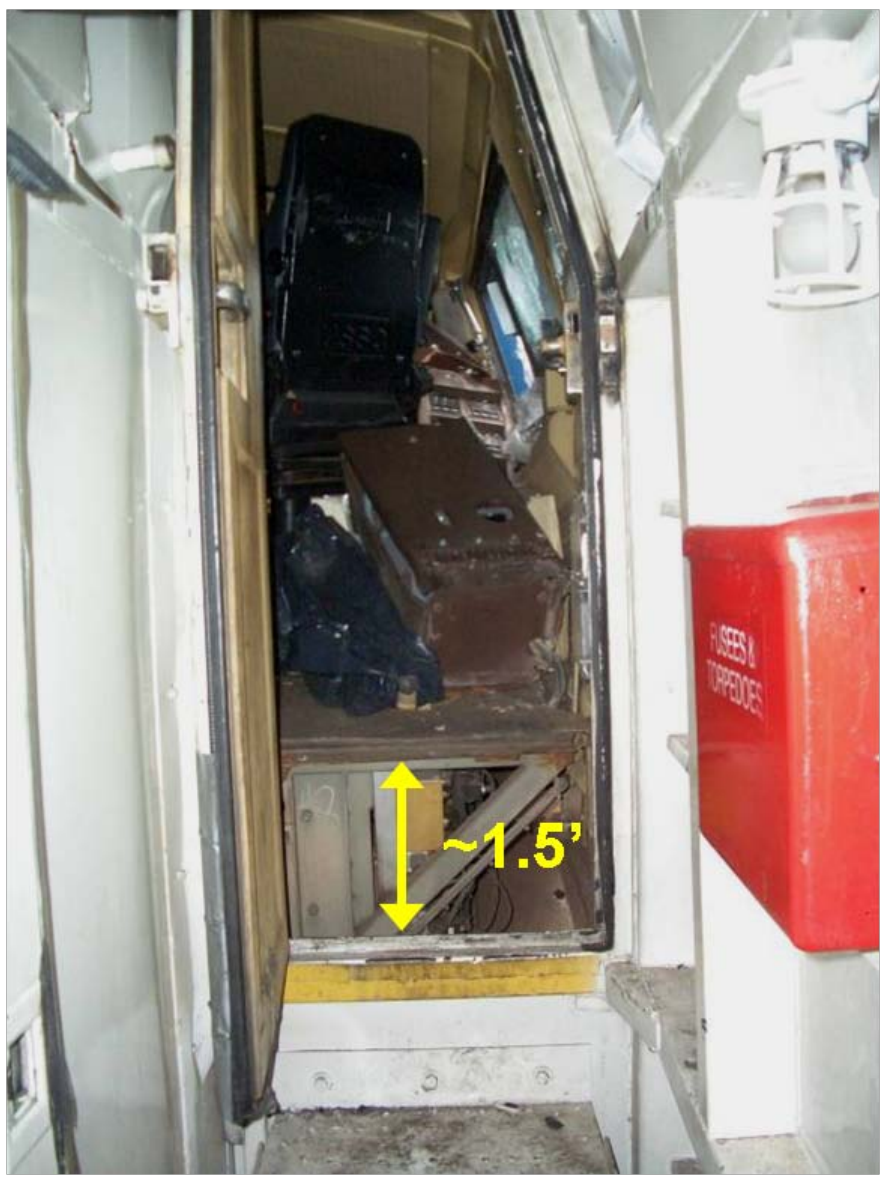

Figure 16. Raised floor of locomotive from impact

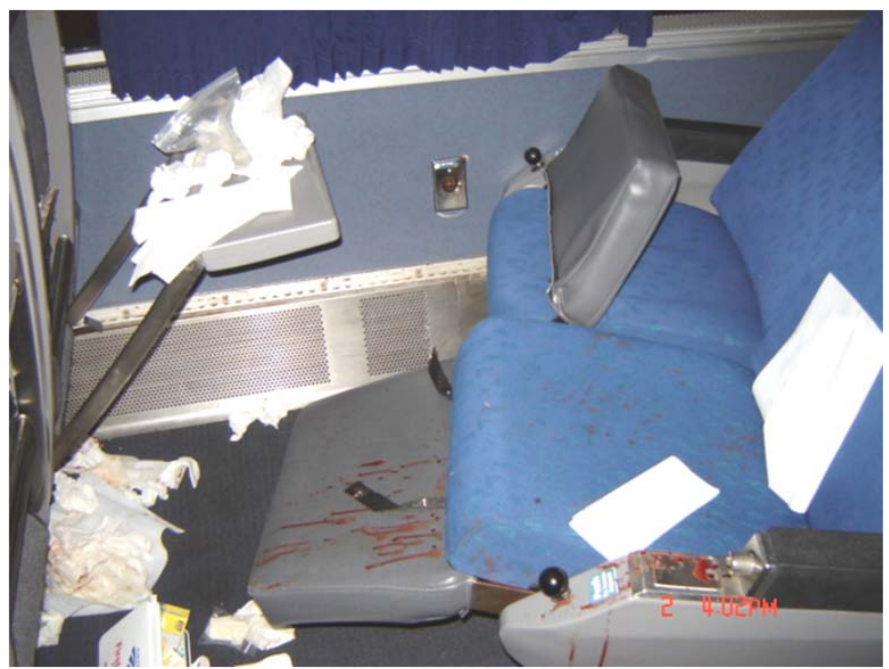

Figure 17. Rotated seat pair.

In addition to the four rotated seat pairs, the middle coach car also had a seat pair that had separated from the wall and floor due to fastener failure, shown in Figure 18. The failed seat pair is believed to have been caused by impact from a standing occupant. The rotated seat pairs in all of the coach cars may also have been caused by impact from standing occupants. 


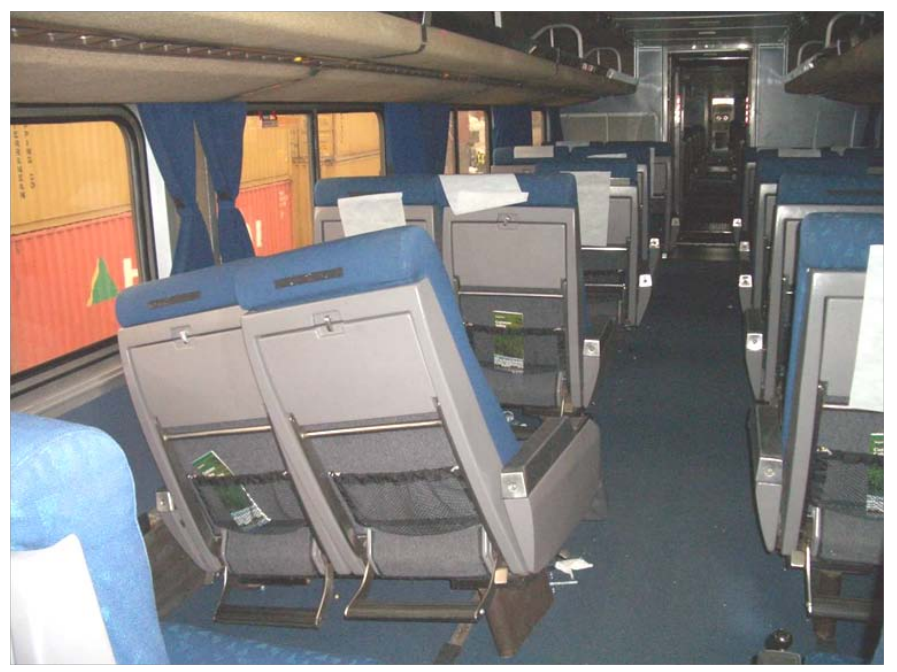

Figure 18. Failed seat pair.

\section{OCCUPANT INJURIES}

The occupants of the Amtrak train included five crew members and 182 passengers. There were no fatalities caused by the accident and no major injuries were incurred by the occupants. Three people were admitted to the hospital overnight, one with a shoulder fracture. It is believed that this person was standing at the time of impact. All patients were released by December 2, 2007, two days after the accident. The injuries of the passengers in the coach cars consisted mostly of bloody noses, small cuts, and bruises. Figure 19 shows evidence of passenger facial impacts with seat backs and Figure 17 shows evidence of a bloody nose injury, all located in the third coach car. No major injuries were sustained by the passengers and crew due to the fact that the passenger train remained in line and the locomotive overrode the freight car rather than being deflected laterally.

The operating engineer and relief engineer located within the operator's cab at the time of impact sustained more severe injuries than the passengers and crew located in the coach cars. This was a result of the locomotive sustaining most of the exterior and interior structural damage and bearing the brunt of the impact. The locomotive underframe deformed upward causing catastrophic failure of the floor of the cab, resulting in the floor and the seats in the cab being pushed upward. This created a situation close to life threatening within the cab, and both engineers could have sustained much more severe injuries than they did. Figure 15 shows the damage to the interior of the cab from the impact. Note that there is very little space left within the cab after the impact. Telephone interviews were conducted of the operating engineer and the relief engineer.
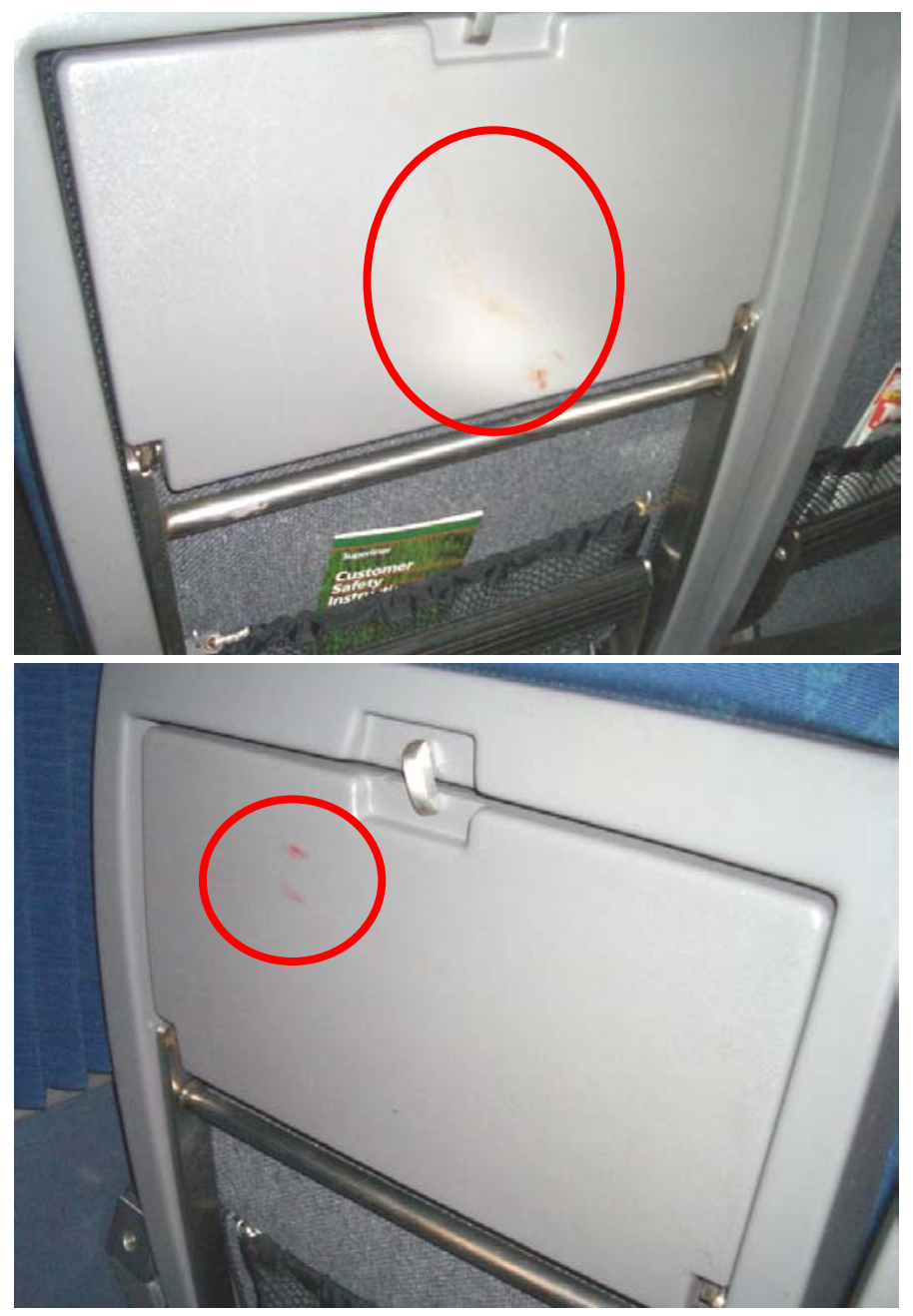

Figure 19. Evidence of passenger injuries from impact with seat backs.

\section{Operating Engineer Interview}

Figure 20 shows the operating engineer's location before and after impact. Prior to impact, the operating engineer indicated that their seat was in the back position and their weight was shifted forward. The operating engineer had both arms extended to the control desktop as they were trying to apply the brakes on the train. The impact caused the operating engineer's body to travel forward and then upward, at which point the operating engineer remembers hitting their head. The operating engineer was then thrown backwards, hitting the rear panel of the cab compartment. The operating engineer came to rest behind and to the left of their seat. Figure 15 shows the damage to the interior of the cab from the impact. Figure 16 shows the cramped space behind the operating engineer's seat where the operating engineer came to rest. The operating engineer sustained a torn meniscus in their left knee, a torn left rotator cuff, a severe concussion, multiple head lacerations, bruises on the left elbow and left ribs, and a sore neck and back. After the accident, the operating engineer was carried out through the rear door of the locomotive. 


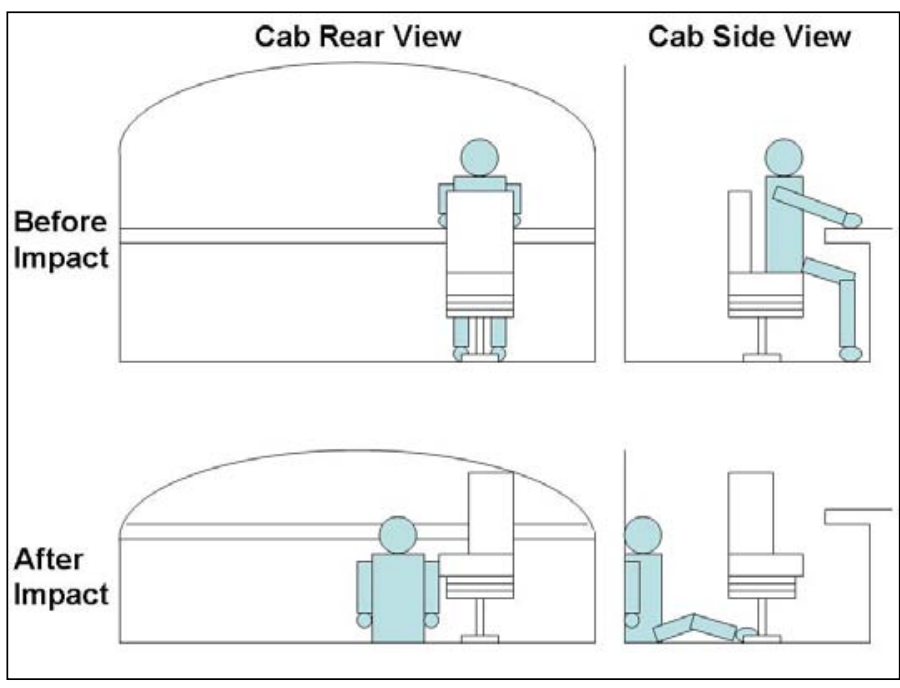

Figure 20. Operating engineer location within the cab before and after impact.

\section{Relief Engineer Interview}

Figure 21 shows the relief engineer's location before and after impact. Prior to impact, the relief engineer indicated that their seat was in the midway position. The relief engineer was fully seated and either looking forward or looking to the right at the operating engineer. The relief engineer does not remember whether or not they extended their arms out to brace against the impact. The relief engineer thinks that the impact caused them to slide off of their seat and underneath the desk, which can be seen in Figure 15. The relief engineer came to rest on their hands and knees facing to the left. The relief engineer sustained a severely broken nose, a head concussion, bruises on their left side, and multiple head lacerations on the left side of their head. The relief engineer thinks that the head lacerations were caused by the heavy metal structure of the seat pedestal, shown in Figure 15. Note that the relief engineer's seat has been pushed into the ceiling of the cab. Had the relief engineer remained in their seat, they might have sustained severe head, neck, and spinal injuries from being pushed into the ceiling by the seat. After the accident, the relief engineer climbed out through a side window and walked away under their own power.

\section{DISCUSSION \& NEXT STEPS}

This paper describes the information gathered from investigating the Chicago, Illinois rail collision of November 30, 2007. At approximately 11:30 am C.S.T., an Amtrak passenger train struck the rear end of a Norfolk Southern freight train at a speed of approximately $33 \mathrm{mph}$. The passenger train, consisting of a leading locomotive and three coach cars, collided with the rear of the last freight car in the freight train. After knuckle-to-knuckle contact, both couplers moved back and their draft gears bottomed out. The draft sill of the freight car deformed downward and the locomotive began to climb the rear of the freight car. The locomotive lead truck engaged the freight car and the locomotive draft gear housing crushed backward and upward. This caused the nose of the locomotive to roll under and the underframe to push up, resulting in loss of occupant volume in the cab compartment. As the locomotive continued to climb the freight car, the lead truck of the locomotive was sheared off, the locomotive rear roof engaged the lead passenger car collision posts and the rear wheel of the lead truck cut the fuel tank of the locomotive. The locomotive lead truck was left behind as the locomotive striker engaged the rear freight container. The locomotive crushed both freight containers and came to a stop on top of them. The locomotive of the passenger train derailed but the coach cars did not and all of the cars remained upright.

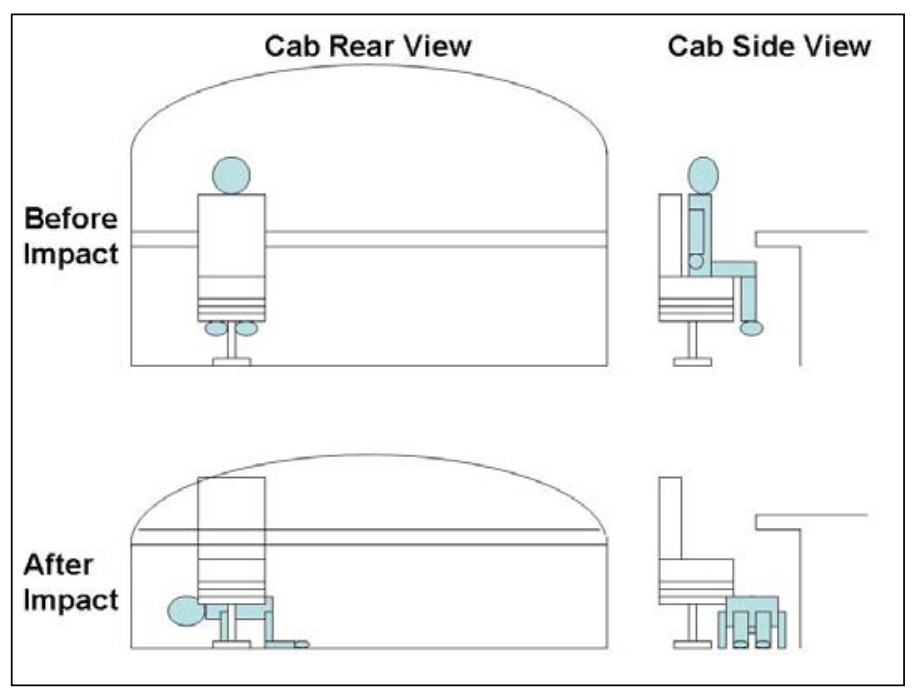

Figure 21. Relief engineer location within the cab before and after impact.

There were no fatalities caused by the accident and only minor injuries were incurred by the occupants. The operating engineer and relief engineer located within the operator's cab at the time of impact sustained more severe injuries than the passengers and crew located in the coach cars. This was due to the fact that the locomotive sustained most of the exterior and interior structural damage and bore the brunt of the impact. The locomotive underframe deformed upward resulting in the floor and the seats in the cab being pushed upward. This created a situation close to life threatening within the cab.

Small changes in the initial conditions of the impact could potentially have resulted in significantly more severe consequences. If the accident had occurred with a slightly higher impact speed, the locomotive may have crushed further, resulting in the complete loss of survival space in the cab. The interactions of conventional equipment when it collides are variable [7] [8]. In the accident, the locomotive overrode the freight car. Small changes in alignment at initial contact may have allowed the freight car to override the locomotive or the freight car and locomotive may have remained engaged. If the freight car had overridden the locomotive, it may have resulted in the operator's cab being directly crushed by the freight car. If the locomotive and freight car had remained engaged, then the 
decelerations of the trailing equipment may have been significantly greater, potentially resulting in more numerous and more severe injuries. The locomotive and freight car remaining engaged could also have led to the trailing passenger equipment laterally buckling onto the adjacent tracks [8] [9]. If the cars had buckled laterally and derailed, there is a very high likelihood that the train would have collided with the trains running on both adjacent tracks, resulting in more severe injuries and possibly fatalities in all of the trains involved.

The next step in the equipment crashworthiness research program is to employ computer models to try to simulate the accident and the behavior of the locomotive and coach cars. Finite element analysis is being considered to evaluate the deformation of the locomotive nose and underframe and how they folded under and upward to displace the cab compartment floor. Preliminary collision dynamics analyses are being conducted to recreate the crash pulse of the accident, to simulate the gross motions of the locomotive and coach cars, and to determine the accelerations imparted to the occupants. Further train collision dynamics analyses are being considered to evaluate the effectiveness of Crash Energy Management features [10] [11] in controlling colliding equipment interactions and occupant compartment decelerations. Occupant dynamics analyses are also being considered to understand the environment within the locomotive cab during the impact, to estimate how the injuries were incurred by the two engineers, and to investigate alternative means of protecting the cab occupants. Passenger seats and their performance in accidents are also being reviewed using data from this and other accidents.

Research is currently being conducted on passenger locomotive crashworthy components such as push-back couplers and deformable anti-climbers that could be integrated into the end structure of a locomotive. The Volpe Center seeks to evaluate the effectiveness of these components that are specifically designed to mitigate the effects of a collision. Acting together, the crashworthy components would allow the ends of the vehicles to engage and they would deform gracefully and predictably, preventing the formation of a ramp. Ideally, had the locomotive in this accident been equipped with these crashworthy components, override might have prevented.

\section{ACKNOWLEDGEMENT}

The research discussed in this paper was performed as part of the Equipment Safety Research Program sponsored by the Office of Research and Development of the FRA. Eloy Martinez, former Program Manager, Office of Railroad Policy and Development, managed the research effort. Kevin Kesler, Chief, Equipment and Operating Practices Division, reviewed and supported the research effort. The authors would like to thank the Primary Forensic Passenger Accident Investigation Team: Charles Whalen, Jennifer Schuster, Mark Sandler, and Peter Lapre, all of the FRA, for their work investigating the Chicago, Illinois train collision.

\section{REFERENCES}

[1] Tyrell, D.C., K.J. Severson, and B.J. Marquis. Crashworthiness of Passenger Trains. Publication DT/FRA/ORD-97/10. Federal Railroad Administration, US Department of Transportation, 1998.

[2] Tyrell, D. "Rail Passenger Equipment Accidents and the Evaluation of Crashworthiness Strategies," presented at 'What can We Realistically Expect from Crashworthiness?' Rail Equipment Crashworthiness Symposium, Institute of Mechanical Engineers, May 2, 2001, London, England.

[3] National Transportation Safety Board, "Collision of Amtrak Passenger Train 371 and Norfolk Southern Railway Company Freight Train 23M , Chicago, Illinois, November 30, 2007," NTSB Railroad Accident Report, PB2009-916301 NTSB/RAR-09/01, March, 2009.

[4] Website:

http://www.gbrx.com/files/files/NAR/Stack_Cars/StackCa rsMaxiIV.pdf. Accessed November 30, 2010.

[5] Website:

http://www.4rr.com/5/50 001.htm. Accessed November $30,2010$.

[6] Associated Press, Accessed December 4, 2007.

[7] Mayville, R., Stringfellow, R., Johnson, K., Landrum, S., "Crashworthiness Design Modifications for Locomotive and Cab Car Anticlimbing Systems," US Department of Transportation, DOT/FRA/ORD-03/05, February 2003.

[8] Tyrell, D. "Rail Passenger Equipment Accidents and the Evaluation of Crashworthiness Strategies," presented at 'What can We Realistically Expect from Crashworthiness?' Rail Equipment Crashworthiness Symposium, Institute of Mechanical Engineers, May 2, 2001, London, England.

[9] Mayville, R.A., Rancatore, R.J., Tegler, L., "Investigation and Simulation of Lateral Buckling in Trains," Proceedings of the 1999 IEEE/ASME Joint Railroad Conference, Institute of Electrical and Electronics Engineers, Catalog Number 99CH36340, 1999.

[10] Tyrell, D.C., Perlman, A.B., "Evaluation of Rail Passenger Equipment Crashworthiness Strategies," Transportation Research Record No. 1825, pp. 8-14, National Academy Press, 2003.

[11] Tyrell, D., Jacobsen, K., Martinez, E., "A Train-to-Train Impact Test of Crash Energy Management Passenger Rail Equipment: Structural Results," American Society of Mechanical Engineers, Paper No. IMECE2006-13597, November 2006. 